Article

\title{
Low Carbon Urban Transitioning in Shenzhen: A Multi-Level Environmental Governance Perspective
}

\author{
Zhanglan Wu, Jie Tang and Dong Wang * \\ Urban Planning, Economics \& Management School, Harbin Institute of Technology, Shenzhen 518055, China; \\ wuzlhit@163.com (Z.W.); jietang@sz.gov.cn (J.T.) \\ * Correspondence: clayton_wang@163.com; Tel.: +86-755-2603-3494
}

Academic Editors: Patricia Romero-Lankao, Mary Hayden and Olga Wilhelmi Received: 19 May 2016; Accepted: 26 July 2016; Published: 29 July 2016

\begin{abstract}
As the world's second largest economy, China ranks among the world's top nations when it comes to carbon emission. Accordingly, its attitude towards climate change is closely followed by all parties concerned. There have been few studies on the role of environmental governance in the transformation process to low-carbon, especially Chinese ones. This study analyzes the impact of government environmental regulation on the low-carbon city transformation process by adopting Shenzhen as the research object. One of the world's youngest super cities, Shenzhen also happens to be the city with the lowest carbon emission intensity in China. The multi-level governance framework is a useful mechanism with which to gauge divisions of responsibility and resources. This paper uses multilevel environmental governance to explain the policy for dealing with the climate in the city of Shenzhen. Striving to explore green low-carbon development path for the whole country, Shenzhen provides practical experience for countries to cope with global climate change.
\end{abstract}

Keywords: urban sustainability; environmental governance; energy policy

\section{Introduction}

Playing a decisive role in the economic and social development, the city is the center of human life and production, more than half of the world's population live in cities. Meanwhile, the urban energy consumption per capita in Asian cities is 3.5 times that of rural areas, and it produces more than $75 \%$ of all greenhouse gases [1]. The speed of urban development, the population size, and job opportunity borne by cities, the wealth created by each industry in cities, the consumption of urban energy, and its pollution of the environment directly influence the development and reformation of a country and even the world. Therefore, cities become the focus for balancing economic development and environmental protection.

After entering into the 21st century and with the process of post-industrialism, energy security and global warming issues caused by human life and production have caused extensive concern at the international level. In a series of solutions, the low-carbon development model which aims at reducing the carbon emission caused by human activities has been universally accepted around the world while also becoming the goal of human development in the new era [2]. From the "low-carbon economy" that utilizes lower consumption of environmental resources producing less environmental pollution but obtaining more economic output, to the concept of "low-carbon society" of the new lifestyle and governance mode of advocating reducing carbon emissions, the concept of low-carbon has been rapidly promoted at every level of production development and social development. Every country successively issues the corresponding programs and plans at the national level to confirm the guiding role of low-carbon concepts on the national development direction. However, as the world's second-largest economy, China's impressive speed of economic development has been accompanied by the same rapid industrialization and urbanization process. Of note is the fact that 
China's energy structure is dominated by coal with a high proportion of the $24.6 \%$ of its total carbon emission ranking at the top of the world [3].

In 2009, at the climate conference in Copenhagen, China promised that its carbon emission intensity $\left(\mathrm{I}=\mathrm{CO}_{2} / \mathrm{GDP}\right)$ will fall by $40 \%-50 \%$ in comparison to 2005 . In 2015 , at the Climate Conference in Paris, it promised that China will cut the carbon intensity of its economy by $60 \%-65 \%$ below 2005 levels by 2030. The realization of the goal put forward by China on the international community requires it to act on all kinds of domestic environmental policies, and then there is China's Five-Year Plan which refers to China's short- and medium-term planning of the national economy and social development [4]. A five-year emission reduction control target of carbon emission by China includes decomposing to the local from top down and it is assessed each year. The outline of 11th national Five-Year Plan (2006-2010) and the 12th national Five-Year Plan (2011-2015) defines the specific targets of controlling carbon emissions and its detailed measures. China strives to transform and develop the low-carbon economy to ensure economic development and also positively responds to the global environmental crisis from a political standpoint. In this aspect, China's proposed low-carbon city works towards meeting demands. In 2011, the country launched construction of the national low-carbon city project, which includes five provinces and eight cities while at the same time a lot of other cities were also placed on the list towards fulfilling this goal. Currently, more than 100 Chinese cities have put forward the goal of creating low-carbon cities.

There are few studies on the role of environmental governance in the transformation process of low-carbon cities, particularly Chinese ones. By adopting the city of Shenzhen, China as the research object and through the perspective of multi-level environmental governance, this study aims to conduct deeper research on the influence of the environmental governance on the low-carbon city transformation. Shenzhen is the first special economic zone established by China's reform and opening up policy program, and one of the four first-tier cities. In 2015, the permanent resident population in Shenzhen was 10.77 million, while the per capita GDP was USD 25,038. As one of the first group of China's 13 pilot low-carbon cities and seven carbon emission trading pilot areas, Shenzhen actively explores the future of sustainable development in China, and provides materials which can be used, for example, for the development of low-carbon cities in China and even in other developing countries.

This paper analyzes the role played by the government in the environmental governance of the transformation process of low-carbon cities by adopting Shenzhen as the object of research. The structure of this paper is listed as follows. In Section 2, low-carbon cities and the multi-level environmental governance theory is analyzed. The relevant methods involved into the research are posited in Section 3. Section 4 focuses on discussing China's multi-level environmental governance system. In Section 5, the multi-level governance in low-carbon urban transitioning is discussed in the context of the experience in China and Shenzhen. Section 6 looks at the specific energy conservation and emission reduction policies in Shenzhen. Section 7 discusses relevant issues. Section 8 presents the drawn conclusions.

\section{Theoretical Background}

\subsection{Low-Carbon Cities}

The research on low-carbon cities can be divided into two aspects, those of macroscopical studies and microscopical studies. Macroscopical studies can be summarized as population and economic growth in the process of urbanization, urban expansion, low-carbon technology progress, low-carbon urban policy, institutional innovation, and energy structure relied on by cities. Research shows that there are Linear [5], Inverted U-shaped [6], and N-type [7] relationships between carbon emission and per capita GDP in different areas; urban expansion changes the urban pattern and function, which leads to the change of carbon emission opportunity, spatial distribution patterns, and construction [8]; the advanced low-carbon technologies include carbon emission reduction technology, low-carbon energy utilization, and carbon capture and storage (CCS) [9], all of which directly influence the 
carbon emission level and also the cost of urban production and consumption [10]; urban policies are the effective means of pursuing sustainable development and realizing low-carbon emissions [11]; the urban clean development mechanism (CDM) [12], emissions trading scheme (ETS) [13], urban regional carbon management (URCM) [14], and other global and local climate policies would be implemented at regional and urban level, while carbon tax [15], rationed exchange, and carbon credit are common policy tools [16]; urban energy structure meanwhile largely determines the strength of urban carbon emission [17].

Microscopical studies are exterior, while micro-level factors influence the urban carbon emission fundamentally. Bristowa et al. shows that if it does not consider behavioral change, even the most significant technical progress can not satisfy the goal of carbon reduction [18]. Carbon emission is calculated from two aspects of production and consumption at the micro level, while its production account includes industry [19], construction industry [20], transportation industry [21], business [22] and the hotel service industry [23]. The consumption of carbon emission account covers the relevant activities of human food, clothing, shelter, transportation, and entertainment. The research on production accounts of cities is relatively common, but it only considers the direct carbon emission of urban 'point locations' and ignores urban carbon leakage. The carbon emission intensity generated by urban production and consumption reflects on the carbon-based energy consumption. The energy structure and the emission intensity are important indicator variables, and it forms the basis on which a lot of scholars analyze the carbon emission of industry [24], family [25], and transportation (private car [26] and freight car [27]) in different city departments.

\subsection{The Framework of Multi-Level Environmental Governance}

The multi-level governance perspective provides academics with a well fleshed-out framework for understanding the relationship between social and technological developments [28]. Traditionally, the study of urban politics has been relatively neglected in the field of political studies $[29,30]$. Recent years have seen a shift in the form and distribution of governing power in national politics, once the near exclusive purview of national governments utilizing vertically-governed policy making, the role of local governance in influencing national politics has grown significantly in recent years. These changes have been met with an increased interest in supranational politics within the field of political studies, and the popularization of the global environmental governance [31-34]. Due to the fact that globalizing cities are the natural sites for studying changes in national and global articulations, and are themselves heavily influenced by national, global, and urban processes, it has become increasingly difficult (and counterproductive) to study global environmental governance and urban governance in isolation. This has led to the integration of urban and global environmental governance research approaches into a single, multilevel approach [35]. City-regions have become ever more important institution sites, as the urban governance of these regions has become the political mechanism by which fundamental changes to national states have been enacted, transforming entire landscapes, evidence of a redistribution of state power [36].

Horizontal collaboration in the context of multi-level governance refers to intra-metropolitan climate governance and city networking, whereas vertical collaboration refers to any and all forms of governance, be they authoritative, enabling, or financial (via funding schemes) [37]. The majority of climate change mitigation policies still merely encourage voluntary action on behalf of local authorities, as the majority of national governments the world over have contented themselves to simply enable modes of governing. Individual cities therefore, tend to choose how they respond to such climate change mitigation policies [38]. Their strategies for doing so, and the processes by which these responses are formulated and reformulated can be examined through a framework for considering both the vertical and horizontal governance procedures, developed to conceptualize the processes of multi-level governance [39].

This framework therefore aids in our understanding of how power, resources and work are allocated via either vertical or horizontal processes. In vertical terms, power is negotiated and 
resources distributed amongst various levels within a single government. In horizontal terms, this refers to the movement of resources and power between networks of interdependent state and non-state authorities [40]. The traditional paradigm of top-down governance with government positioned at the head of society and tasked with ruling on its behalf can therefore be seen to have changed in recent years. Governance is now less hierarchal, and power is less concentrated, operating through an interdependent network which transcends formal organizational borders, and it is the multi-level governance framework which affords us the ability to accurately gauge the nature and extent of this distribution of power and resources, allowing researchers to examine governance from a broader perspective.

\section{Methods}

The authors conducted this study by relying on qualitative research methods: (1) A field survey and literature review were conducted to systematically study the low-carbon urban transitioning processes. The paper consists of a huge amount of data on energy and climate change mitigation from academic studies, policy documents, the China Statistical Yearbook, and media coverage related to China, especially to Shenzhen; (2) Key person interviews and in-depth interviews were used during the investigation. Specifically, this study collected correlative information in Shenzhen by interviewing key persons. The National Development and Reform Commission (NDRC), which has 28 functional institutions, is one of China's organs of power. One of its functions is responsible for relevant works on mitigating climate change, energy conservation, and emission reduction. Shenzhen Development and Reform Commission (SDRC) is affiliated with NDRC, and mainly takes charge of implementing various national policies on economic development. Therefore, the policies about low-carbon transition in Shenzhen mostly stem from NDRC and SDRC. Deputy Mayor of Shenzhen supervises SDRC directly, while the director of SDRC is specifically responsible for coordinating and carrying out urban construction to mitigate climate change, organize and implement Clean Development Mechanisms, and so forth. So the authors chose the deputy mayor and director of SDRC as the interviewees.

\section{China's Multi-Level Environmental Governance System}

Environmental governance is very important for coping with climate problems and transformation of the low-carbon city. In China's policy system, as the top designer, the State Council has right to formulate the emission reduction policy and the relevant administrative regulations. The provincial government is guided by the central government policy, and is responsible for the carbon emission reduction work of the enterprises and the public within the province. Meanwhile, only the provincial government has direct relations with the central government; the prefectural and county-level governments do not have this direct relationship with the central government. Each province fixes energy conservation, emissions reduction and carbon reduction indexes, quantifies tasks, implements them into every city, and guarantees to complete the overall goals of emission reduction in the central government's Five-Year Plan.

According to the characteristics of environmental policy instruments and their evolution, environmental policy can be divided into three types: command-control type regulation; policy instruments based on market instruments; and voluntary environmental regulations. The command-control type regulation policy can realize the relative high regulation effect but where the regulation cost is relative low and lacks overall efficiency. Because it does not take the cost difference of the person who is regulated into consideration, it will cause social welfare loss and is not beneficial for enterprises' technical innovation. However, because the command-control type regulation policy is easy to implement, it is widely-applied in China. The country's command-control type regulation is particularly prominent in the aspect of environmental management. The Chinese national government initiates the environmental protection target responsibility system for the environmental protection industry, which is the administrative management system of local governments at various levels concretely taking charge of 
environmental quality through the form of signing the liability statement. To be specific, the responsible person from the local government regulates the emission reduction goals and tasks, which will be achieved within the tenure, with the signing of the environmental protection liability statement form along with establishing the corresponding assessment and rewards and punishments measures as well as carrying out the rewards and punishments according to the completion situation of goals, and taking it as one of the contents of government performance examination. Meanwhile, the central government gives the local government a certain tax right and expenditure liability scope, allowing it to autonomously determine the budget expenditure scale and structure, and actively participate in social management, such as the budget of emission reduction used in this paper.

The realization of China's emission reduction goals mainly depends on the implementation of environmental protection objective responsibility, namely, the government environmental protection goals' liability statement. It is also China's multi-level environmental governance link. The Letters of Responsibility are signed from the top to bottom levels by the central and provincial governors, the governors and mayors, mayors and county mayors, as well as the head of the city and county level, and the legal personnel of related units. After being formulated, the government departments at all levels formally issue the responsibility target to each responsibility unit, and decompose the indicators step by step, to establish a responsibility system at all levels, so as to quantify the task and responsibility being implemented. After the issuance of the Letters of Responsibility under the unified guidance of the government, the responsible units separately organize the implementation according to their respective tasks. The government and relevant departments of responsibility carry on a regular inspection and take effective measures to ensure the completion of the target responsibility. Once the next level of government finishes the target task during their tenure, they will be rewarded by the higher levels of government, while those who fail to complete the task are punished. Figure 1 shows the multi-level environmental management system in China.

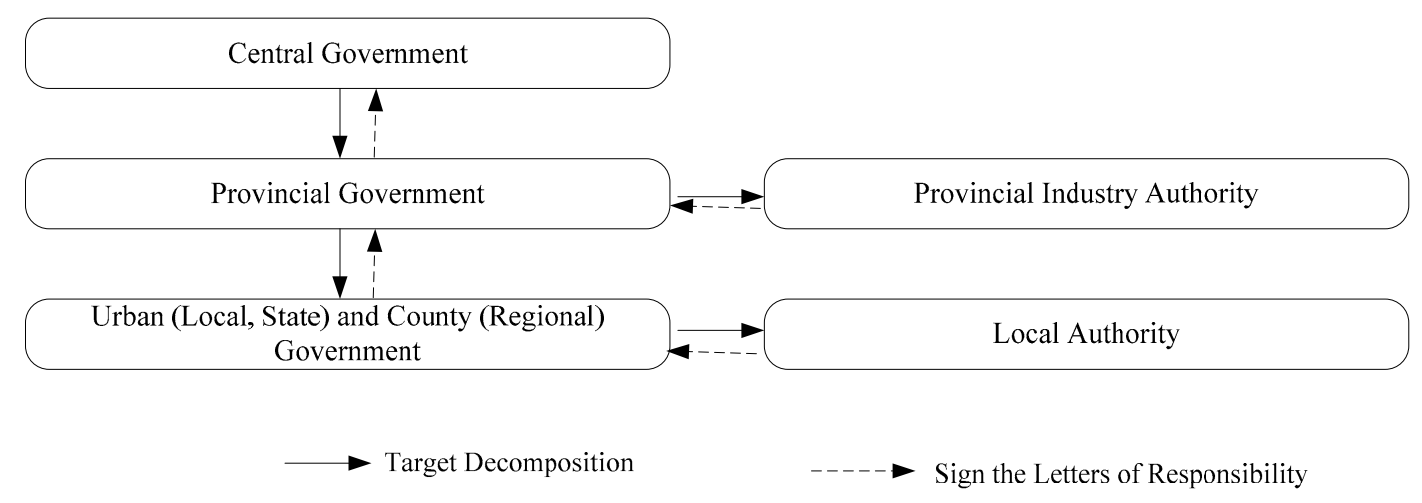

Figure 1. China's multi-level environmental governance system.

\section{Multi-Level Governance in Low-Carbon Urban Transitioning-The China and Shenzhen Context}

\subsection{The National Policy Settings}

In 1990, China established the "National Climate Change Coordination Group" under the Environment Protection Committee (EPC), which is responsible for coordinating and formulating the polices and measures related to climate change. In 1998, it was reorganized as "Weather Evaluation Coordination Group of the State Council", which consisted of the Chinese Academy of Sciences and 15 members of ministries and commissions. In 2007, the group was upgraded to the "National Leading Group for Climate Change, Energy Conservation and Emissions Reduction", whose function was to study and formulate national important strategies, principles, and policies to deal with climate change, and also to organize and fulfill the energy conservation and emission reduction policy determined by the state council. The leading group consists of China's prime minister, who is the group leader, 
the deputy prime minister, who is the deputy group leader, and 29 directors of the ministries and commissions who are the members of the group. Under the charge of the leading group, the Office of National Leading Group for Climate Change and the Office of National Leading Group for Energy Conservation and Emission Reduction are set in National Development and Reform Commission (NDRC). To respond to climate change, NDRC sets a centralized management institution. The leading group that deals with climate change led by NDRC coordinates and contacts the management institution to guide in the specific work of the leading group responsible for climate change as well as energy conservation and emissions reduction. NDRC has established a special department to deal with climate change responsible for specific work on the problems of climate change, and also set up a special department of resource conservation and environmental protection to deal with the daily work of energy saving and emission reduction. At the same time, the country also set up an energy commission and energy bureau responsible for the reform of the energy problem closely linked with climate. In addition, the NDRC is in charge of climate change duties while the relevant central authorities are responsible for the specific areas. The MIIT, MOHURD, NBS, China Meteorological Bureau, and CAAC have gradually set up special departments to be responsible for the relevant work of climate change. The department of agriculture and the ministry of finance have also strengthened the research and deployment of tackling climate change in their related fields [41]. The Chinese government has attached great importance to the work on climate change, energy conservation, and emission reduction.

In regard to China's economic development and energy demand, the adopted reduction goal is to reduce the proportion of carbon intensity and adjust carbon intensity mode of $\mathrm{I}=\mathrm{CO}_{2} / \mathrm{GDP}$, complying with China's current national condition and fundamental interests. China's overall goal towards emission reduction for 2030 is to reduce carbon intensity by $60 \%-65 \%$ below 2005 levels. The 13th Five-Year Plan (2016-2020) will continue to set up a strong carbon emissions control objective, so as to achieve the aim of reducing the carbon intensity by $40 \%-45 \%$ by year 2020 from 2005 levels. In order to achieve this goal, China will take administrative measures such as implementing a responsibility system and encouraging enterprises as well as the society at large to achieve the goal in price, tax, financial, and fiscal incentive policy areas. Another method will be to adopt the market practice, for example, China has approved seven cities-namely Beijing, Shanghai, Shenzhen and others - to carry out experiments on a carbon emission trading scheme. Among the most important ways to achieve low-carbon and emission reduction includes technological innovation and improving national consciousness for green low-carbon development. China will take measures in this respect. In 2010, the country identified five provinces and eight cities as the first batch of national low-carbon plots. However, China does not collect carbon tax separately, but includes it in the existing tax structure, such as the environmental tax or the resource tax. In fact, even in the absence of environmental taxes or resource taxes, the current consumption tax collects carbon tax indirectly. After being adjusted, the focus of China's consumption tax is to collect from the products related to high-energy consumption, high-pollution, and high grade.

\subsection{Shenzhen Policy Settings}

A coastal city of Guangdong province, Shenzhen is located on the eastern coast of the Pearl River Delta in south China, facing Hong Kong across the river. It is China's first special economic zone and has been 30 years in construction and development, having been developed from a former small border town into an emerging modern metropolis with international influence. Created at a remarkable speed, Shenzhen is a shining example to the world in urbanization, industrialization and modernization. Its GDP tendency chart for the past years is in Figure 2. The city is one of the gateways connecting with the world as it possesses the most ports and can be considered an exclusive city with ports of sea, land, and air; vigorous economic support; and modern urban infrastructure. Shenzhen's land area equals to one-eighth the land of Beijing, while its population density reaches to 5398 per square kilometer, which ranks top in China [42]. 


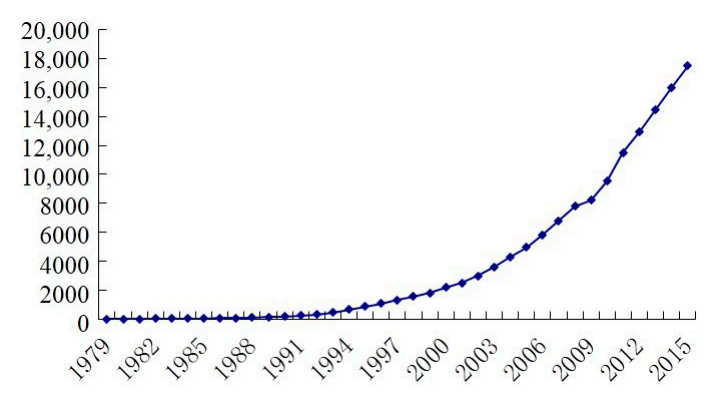

Figure 2. Shenzhen GDP variation tendency (million yuan).

Based on the research on the data of energy consumption, the $\mathrm{CO}_{2}$ emission of Shenzhen in 2010 was 106 million tons. Unlike most cities in China, the $\mathrm{CO}_{2}$ emission of most cities in China was dominated by coal consumption while Shenzhen's carbon consumption was primarily from electricity consumption which accounted for $36 \%$ of the total emission volume. Therefore, saving electricity is one of the key components of carbon emission reduction for Shenzhen. The industrial carbon emission of Shenzhen accounts for $55 \%$, while the carbon emission of the service industry moves up to $32 \%$ [43]. Moreover, the service industry is gradually becoming the pillar of economic force. Judging from the industry development trend, Shenzhen is set to step into the postindustrial stage predominated by service industry through this process, the energy conservation and emission reduction of the service industry and people's livelihood consumption should be fully enhanced. The people's livelihood and carbon consumption stems from building electricity consumption and transport use.

\section{Shenzhen: Climate Policy and Low-Carbon Urban Transiting}

After the central government had established leading institutions for mitigating climate change and energy conservation and emission reduction, each provincial government established corresponding departments. In the mode of institutional construction, the provincial government will be under the central government, and the team leader of the climate change governance group will be the governor or principal leader of the province. As the special economic zone of China (Fiscal revenue and expenditure of Shenzhen has taken charge of the central government, administration part of Guangdong Province), the city formed its governance group at a corresponding level to tackle climate change issues, take charge of the formulation, and implement climate change governance scenarios and related planning and staffing in the Shenzhen area, as well as organize a clean development mechanism program.

In recent years, Shenzhen has been making considerable progress on clean production, recycling, and green building while realizing a rapid reduction in energy consumption index. It has thus edged itself into the first batch of national low-carbon pilot cities. In 2005, the GDP unit energy consumption was 0.59 ton/10,000 Yuan, which was considerably lower than the national average of China. Commendably, although the energy consumption index is relatively low, Shenzhen continuously strives for energy conservation and emission reduction, bucking the trend of successive fall over the years. Shenzhen's statistic yearbook shows that it had fulfilled the annual energy conservation targets set for 2011-2013 with the GDP unit energy consumption of 2011 reduced by $4.39 \%$ equating to 0.472 tce/10,000 Yuan; the data of 2012 was reduced by $4.51 \%$, equating to 0.451 tce /10,000 Yuan; the data of 2013 however exceeds $5 \%$ at $5.12 \%$ while the GDP unit energy consumption reached 0.428 tce $/ 10,000$ Yuan. It cumulatively accomplished the target of $66.13 \%$ set by 12th Five-Year Plan, exceeding $6.13 \%$ of the target. While horizontally comparing with the rest of the cites in Guangdong province, its GDP unit energy consumption per 10,000 Yuan is the lowest, less than $70 \%$ of the country's average index. Compared with other small and medium-sized cities in China, Shenzhen plays an outstanding role in energy conservation and emission reduction. In 2013, its GDP unit energy consumption was only slightly higher than Beijing, which was 0.425 tce/10,000 Yuan, and indeed remarkably lower than Guangzhou, which was at 0.482 tce/10,000 Yuan, and also Shanghai, 
which was at 0.542 tce/10,000 Yuan. The GDP unit energy consumption of Shenzhen in past years shall be seen in Figure 3.

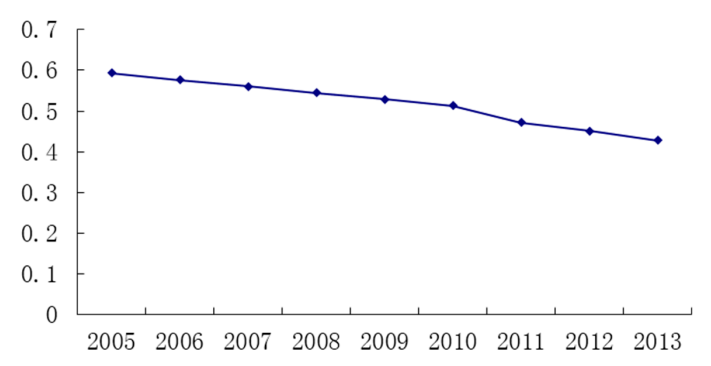

Figure 3. Energy Consumption per Unit of GDP (ton of SCE/10,000 yuan).

Shenzhen is one of China's first lot of low-carbon pilot cities and carbon-trading pilot cities. In the special management system in China, the local government absolutely implements the central government's policies. As the management system in China is multi-level, Shenzhen, as a special city, is supervised by the central government and assumes the tasks of reduction emissions given by the superior. According to the central government's Five-Year Plan, Shenzhen has formulated a long-term low-carbon development plan (2011-2020), with the specific low-carbon development goal mainly as shown in Table 1 [44].

Table 1. Major goals of Shenzhen low-carbon development.

\begin{tabular}{|c|c|c|c|c|}
\hline Category & Index & Unit & 2015 & 2020 \\
\hline \multirow[t]{10}{*}{$\begin{array}{l}\text { Low-Carbon } \\
\text { Output }\end{array}$} & Reduction rate of carbon intensity & $\%$ & 39 & 45 \\
\hline & Carbon intensity & Tons of $\mathrm{CO}_{2} / 10,000$ yuan & 0.90 & 0.81 \\
\hline & Energy consumption per unit GDP & Tons of SCE/10,000 yuan & 0.398 & 0.366 \\
\hline & High and new technology industry increase of GDP & $\%$ & 35 & 40 \\
\hline & $\begin{array}{l}\text { Added value of modern service industry accounting } \\
\text { for the proportion of the tertiary industry }\end{array}$ & $\%$ & 60 & 65 \\
\hline & Added value of strategic emerging industry of GDP & $\%$ & 40 & 50 \\
\hline & Unit energy consumption of industrial production & ton of SCE/10,000 yuan & 0.394 & 0.355 \\
\hline & Proportion of green buildings among new buildings & $\%$ & 40 & 80 \\
\hline & $\begin{array}{l}\text { Share rate of public transport among } \\
\text { motorized travel }\end{array}$ & $\%$ & 56 & 65 \\
\hline & New energy car ownership & 10,000 units & 5 & 10 \\
\hline \multirow[t]{5}{*}{$\begin{array}{l}\text { Low-Carbon } \\
\text { Resources }\end{array}$} & Proportion of fossil energy in Primary energy & $\%$ & 15 & $>15$ \\
\hline & Proportion of clean energy in energy consumption & $\%$ & 50 & 60 \\
\hline & Forest coverage rate & $\%$ & 41.2 & $\geqslant 41.2$ \\
\hline & Green mileage per unit area & $\mathrm{Km} / \mathrm{sq} \mathrm{km}$ & 1.0 & $\geqslant 1.0$ \\
\hline & Park green land area per capita & $\mathrm{m}^{2} /$ person & 16.9 & 17.4 \\
\hline \multirow[t]{4}{*}{$\begin{array}{l}\text { Low-carbon } \\
\text { Environment }\end{array}$} & Proportion of R\&D spending in GDP & $\%$ & 4.0 & 4.5 \\
\hline & $\begin{array}{l}\text { Proportion of low-carbon technology in } \\
\text { R\&D spending }\end{array}$ & $\%$ & 10 & 15 \\
\hline & $\begin{array}{l}\text { Carbon emissions statistics, calculation and } \\
\text { evaluation system }\end{array}$ & - & Basically built & More perfect \\
\hline & $\begin{array}{l}\text { Cognitive rate of citizens to the concept } \\
\text { of low-carbon }\end{array}$ & $\%$ & 80 & 90 \\
\hline
\end{tabular}




\subsection{Specific Measures for Shenzhen in Reducing Energy Consumption}

\subsubsection{Local Government Performance Evaluation}

In order to facilitate the low-carbon development of Shenzhen, its government has established a leading group in the party committees as well as in government as the leading cadre evaluation mechanism on environmental performance to take the outcome of the evaluation as one of the important parameters to appoint, dismiss, reward, and penalize the cadres. The implementation of Shenzhen Environmental Protection Performance Evaluation Regulation is under the direct leadership of the Shenzhen party committee and government leadership, which is initiated by the Department of Organization and the Municipal Committee of Shenzhen. The primary principals of the divisions, departments, and districts are appointed to be the first principals in charge. This top-down organization structure is considered a decisive factor towards ensuring a high-quality evaluation system. The result of the evaluation is regarded to be one of the parameters of assessment for the political achievement, annual appraisal, and selection and appointment of a leading cadre, which is a mandatory constraint to the evaluation objective. Leading cadres who failed in the evaluation will not be appointed to important positions within a two-year period; and primary leaders or branch leaders who do not qualify as a result of not achieving the required marks and ranks last in the evaluation will be sent to carry on persuasion and admonition with city leaders; the department which ranks last and is inadequate to meet the required score of 70 out of 100 will receive a yellow card warning. The invigilators of environmental evaluation consist of party representative, NPC member, CPPCC members and guest monitors, specialists in ecological environmental protection, environmental protection supervisors, environmental protection citizens, and various jurisdictions' residents from all parts of the city, who will listen to the actual report of the examined unit on low-carbon emissions and environmental protection as well as other related work on site. Although the assessment activities are organized by the official, the examiner is a third-party panel composed of public representatives. Shenzhen has created an on-site review form of environmental assessment for the first time in China, wherein it will have presentations, field defense, on-site review, and published scores on site. However, the evaluation index data comes from various government departments or is entrusted to a third party to organize investigation. In addition, public satisfaction is an important link in the design of appraisal system. In order to guarantee the randomness of a survey and the fair justice of the results, the survey carried out on public satisfaction will be implemented by the statistical department, who will entrust a third party to carry out the investigation. According to the principle of random sampling, combining household surveys and telephone interview surveys will bring out the true feeling of the residents towards environment and also evaluates public opinion through an objective questionnaire.

\subsubsection{Industrial Structure Upgrading}

The low-carbon development of Shenzhen has been accelerated by the upgrading of industrial structure. Shenzhen has enhanced efforts towards eliminating high-energy consumption, high-pollution emission and low-productivity in various industries including chemical and building construction. Meanwhile, 3074 high-energy consumption enterprises had been eliminated in 2014 alone. During the period of the 12th Five-Year Plan, the industries which met the requirement of low-carbon development such as biological, IT, new energy, new material, culture innovation, and six strategic emerging sectors were actively encouraged with over 2000 projects supported by the Shenzhen government. The service industry with low energy consumption and low emission became the engine in line with the strategic emerging industry, accounting for 56\% of Shenzhen's GDP. A batch of low energy consumption in per value-added industries and enterprises with core competitiveness were fostered and developed in Shenzhen, which was effectively pulling down the GDP unit energy consumption of the city while promoting the economic development at a higher speed. 


\subsubsection{Developing Cleaner Energy}

The methods of emission reduction should emphasize reducing the coal consumption proportion in energy consumption. Shenzhen therefore vigorously promotes natural gas. In 2006, with the light ceremony started by the Prime Ministers of China and Australia, the first-phase of Guangdong LNG project was founded and put into operation after 11 years of preparation and construction with clean natural gas coming all the way from Australia by sea and used by families across Shenzhen. It marked Shenzhen's entry into the era of natural gas. In 2012, the successful completion of the second stage west-east natural gas project raised the curtain for Shenzhen to implement further adjustment of energy structure and improvement of atmosphere environment. During the seven years from 2006 to 2013, Shenzhen consumed 13.5 billion cubic meter of natural gas, which cumulatively reduced approximately 7.9 million tons of greenhouse gas emission. In 2012 alone, Shenzhen supplied the city with 2.8 billion cubic meters of various natural gases, which was equivalent to saving approximately 2.77 million cubic meters of heavy oil, and cumulatively reduced approximately 1.65 million tons of greenhouse gas emission, 11,000 tons of $\mathrm{SO}_{2}$ emission, 2900 tons of nitrogen oxide emissions, and 1300 tons of PM2.5 emissions [45]. In addition, Shenzhen endeavored to develop renewable resources, actively carrying out the photovoltaic power generation, and vigorously developing biomass energy. In 2006, it took the lead to launch Shenzhen Special Economic Zone Building Energy Conservation Regulation to enforce the installation of solar heating systems in buildings under 12 floors, thus initiating the compulsory promotion of solar heating systems nationwide [46].

\subsubsection{Development of New Energy Vehicles}

As the country's first batch of new energy vehicle demonstration pilot cities as well as the first batch of private purchase of new energy vehicles subsidies pilot cities, Shenzhen has made remarkable achievements in recent years, whether it's in the promotion of new energy vehicles or the development of industry. The city has China's leading new energy vehicle Enterprise-Shenzhen BYD. In September 2014, New York held the global city alliance C40 "Global City Climate Leadership Award" award ceremony, in which Shenzhen won despite a number of famous cities competing and obtained "Global City Traffic Leadership Award" for the innovative model in the operation of new energy vehicles. In December 2014, Shenzhen began the property-purchasing limitations for ordinary cars, which provided a good opportunity for the development of new energy vehicles. We can discover from Figure 4 that after the purchasing policy, the extension quantity of Shenzhen's new energy vehicles grew rapidly in 2015. According to the Shenzhen New Energy Development Program in 2015 , by the end of that year, the total amount of promotion and application of new energy vehicles was more than 28,000, among which the new energy bus inventory was more than 4500 ; the pure electric taxis inventory was more than 4500 ; the newly-increased pure electric logistics and sanitation vehicles reached more than 3500; newly-increased pure electric commuter buses more than 2000; and newly-increased new energy vehicles of individuals, social organizations, and enterprises reached more than 10,000 [47]. Shenzhen has become the world's largest city in the area of public transport and in the application of new energy vehicles. The promotion model of Shenzhen's new energy vehicles has shown the world that a big city can achieve the goal of "low-carbon" by using electric buses. 


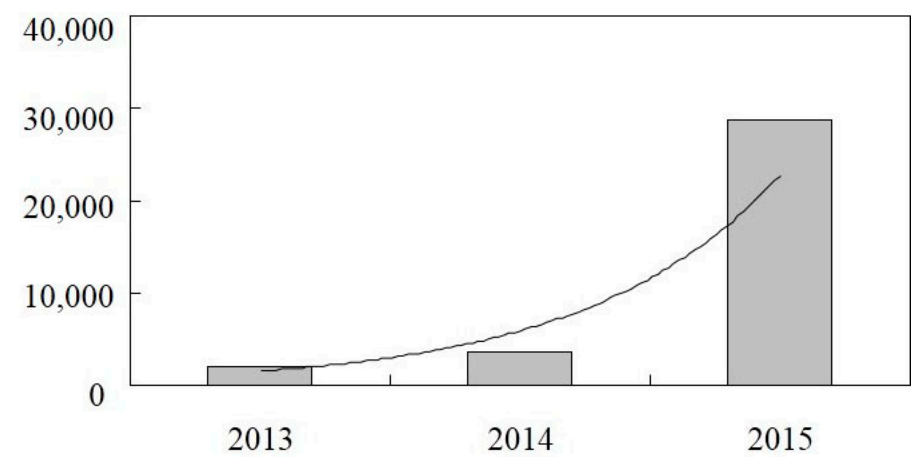

Figure 4. Promotion of Shenzhen new energy cars.

\subsection{Carbon Emission Trading of Shenzhen and Pilot City of Low-Carbon}

Put into operation in 2013, the carbon emissions permit trading in Shenzhen was China's first formal mandatory carbon market and marked the significant step towards the carbon market construction of China. In this round of carbon trading, the Shenzhen government chose 635 enterprises and 197 large public buildings as the carbon emission regulation units, of which the enterprises whose annual carbon emission exceeding 5000 tons account for $40 \%$ of the emission volume of the whole city [3]. There are 635 industrial enterprises entitled to reach 100 million tons of quota in 2013-2015 in summary. Compared with that of 2010, the average carbon intensity of these enterprises decreased by $32 \%$ by 2015 , the rate of average annual reduction of carbon intensity in $2013-2015$ reaches $6.68 \%$, and the data is higher than $21 \%$, which is the city's average emission reduction target, as well as the reduction target of "carbon intensity" in manufacturing industry, which is $25 \%$. In 2014, the Shenzhen Emission Permit Exchange approved by State Administration of Foreign Exchange became the first domestic carbon trading platform allowing foreign investors to participate without any interference and restriction of quota and currency. In 2016, British Petroleum (BP) and Mawan power held by Shenzhen energy completed the first carbon asset repurchase transaction in the Shenzhen Emission Permit Exchange, whose objects reached the quota of four million tons, which was the largest transaction since the carbon trading markets began operating in China's pilot cities. At present, Shenzhen is the most active carbon emission trading market in China, and the regulation units under the charge of Shenzhen Carbon Emission Permit Exchange declined significantly.

In the area of the comprehensive energy-saving pilot, the Shenzhen government actively constructed an international low-carbon pilot, by taking the Gaoqiao District's one square $\mathrm{km}$ as the start zone, and five square km along Xiding Mountain, Gaoqiao District as the development zone, covering 53 square kilometers across the street [48]. It was once called a "cow town" for its low industry, scattered layout, and large energy consumption. After the planning and construction of the low-carbon city, the international low-carbon city was strategically positioned as the climate-friendly city, emerging low-carbon industry gathering area, leading area of the low-carbon way of life, and low-carbon international cooperation demonstration zone by promoting the concept of low-carbon development. In terms of policy and financial support, it built a construction platform that was participated in at multiple levels and also adhered to the guidance of NDRC, Shenzhen key regional headquarters, the national development and reform commission leadership, and the accumulative total investment has reached 20 billion yuan. On planning, Shenzhen adheres to a high starting point plan, and its green traffic system has improved gradually through the layout of low-carbon city and low-carbon transport. It also reforms the old plant by taking advantage of the modern green low-carbon technology, setting up the urban renewal model, and promoting the research and development of low-carbon building industry as well as by building a new urban model by sharing community resources. In terms of promotion, it regularly organizes global high-end low-carbon BBS each June and perennially holds various international academic seminars and events, so as to intensively promote the low-carbon city's 
visibility and influence. This is the exploration of Shenzhen that carries out the central decision-making and opens the green low-carbon urbanization.

\subsection{Shenzhen NGO Organization}

Non-governmental organizations (NGOs) play an active role in climate change, which has been a topic discussed by the forums and seminars on global climate. However, compared with the impact of NGOs on climate change in the world, their impact on climate change in China is rather restricted and a little weaker. For instance, there are some local NGOs and international NGOs which are working on climate change. Specifically, there are some local NGOs which are actively researching global environmental issues, such as the Global Environmental Institute (GEI), Friends of Nature (FON), Global Village, Green Earth Volunteers, IPE, CCAN, and CYCAN. For example, the working focus of FON is to respond to the increasingly prominent city environmental issues during the rapid urbanization process of Shenzhen. Additionally, FON discusses and seeks the livable city construction methods for Shenzhen through the promotion of front-end garbage reduction, the construction of a low carbon family and community, urban natural experience and environmental education, etc. In addition, it also includes calling attention to and participating in the search for solutions to those serious environmental damage issues. Since Shenzhen and Hong Kong are only separated by a river, the environmental protection NGOs of the two cities often establish cooperative communication, such as the "Shenzhen and Hong Kong Environmental Protection NGO Shenzhen River Visit and Communication Project" in 2014. Their environmental personnel inspected the river and Mangrove Forest Natural Reserve Areas all along the village of Dawang and the reservoir of the Wutong Mountain located at the Shenzhen-River-Bay watershed. Additionally, they extensively promoted the method of "one river, two systems" of the two cities to make a joint effort for the afforestation and reduction of carbon emission. Even though these organizations have started relevant work in Shenzhen, what NGOs can do is limited because of the political systems in China. The main causes for such limitations were: systematic obstruction of management, and inadequate legal system, and insufficient funds.

\section{Discussion}

What is mentioned above mainly studies how Shenzhen is dealing with the climate change and what kind of measures it is taking, and how it is turning into a low-carbon city. The policy in China used to handle climate change relies on multilevel environmental governance. Although, different countries have different measures for climate change, the measures taken in China are quite different from those used in western countries. As for the multilevel environmental governance in China, there are two outstanding features. First, since cities in China are larger and population in each city is larger too, so the policies used by local government will affect more people than that in western countries. Second, central government has the power and right to determine and implement the policies, especially the policies related to safety, economy, energy, public investment, and land use. However, policies on climate change are made by local government under the framework of measures required by central government [49].

This paper uses multilevel environmental governance to explain Shenzhen's policy for dealing with the climate. The city fully executed the climate policy of the central government. As China's city with the most rapid economic development, Shenzhen actively implemented low-carbon urban transformation, on one hand, it undertakes the responsibility of environmental protection, and completes the requirements of national of saving energy and reducing consumption; On the other hand, it adjusts the economic structure, improves energy utilization efficiency, and develops emerging industry, which are consistent with Shenzhen's transformation of the mode of development. Shenzhen develops the economic model based on low energy consumption, low pollution, and low emissions. For Shenzhen, it is a transformation of energy efficient utilization, clean energy development, and the pursuit of green GDP, whose core is energy technology and emission reduction technology innovation, industrial structure, and institutional innovation as well as the 
concept of human survival and development. This is the result of the great transformation of Shenzhen energy and economy, as well as its values. In the future development, Shenzhen will abandon the traditional growth pattern of the 20th century, and realize socially sustainable development through the low-carbon economic model with a low-carbon way of life.

Shenzhen is one of the world's youngest super cities and is also China's lowest carbon emission intensity city. It takes efforts to explore a green low-carbon development path for the whole country and provide practical experience for countries to cope with global climate change. However, all efforts taken by Shenzhen failed to reduce the total quantity of carbon emissions, and what it emphasized was carbon emission intensity, which is consistent with the international commitments made by the central government. Therefore, we can think that it is the avoidance of the central government on carbon emissions that leads the local government to make the same response, which is also a major shortcoming for China's multilevel environmental governance.

\section{Conclusions}

As the world's second largest economy, China ranks as the top of the world in carbon emission. Accordingly, its attitude towards climate change is closely followed by all parties. As Shenzhen is ranked fourth on the GDP ranking of Chinese cities, its local government faces enormous pressure on emission reduction from the central government. By relying on the traditional development model, its economic growth has inevitably been accompanied by an increase in energy consumption. However, Shenzhen maintains the trend of a rapid reduction on the indexes of energy consumption, carbon emission intensity in both the area of GDP and fiscal revenue, which constantly increases. As a result, it needs to be aware that the index going forward will be considered with reference to its economic development, rather than on energy consumption as well as carbon emission output. Low-carbon city transition needs financial support, and for China's coastal cities like Shenzhen, nevermind the subsidies for the new energy vehicles, or the establishment of the carbon emission trading system, there is no doubt that the Shenzhen government has spent considerable manpower and financial resources. Its economic strength is unmatched by many small and medium-sized cities in China, and finding ways to implement its layered management system in other cities would be the focus of later research.

Acknowledgments: Financial support by Theory Research Program of Guangdong (No. LLYJ1310) is acknowledged.

Author Contributions: Zhanglan Wu and Jie Tang conceived and designed the experiments; Jie Tang and Dong Wang contributed materials; Zhanglan $\mathrm{Wu}$ wrote the paper.

Conflicts of Interest: The authors declare no conflict of interest.

\section{References}

1. World Wide Fund (WWF). Mega-Stress for Mega-Cities: A Climate Vulnerability Ranking of Major Coastal Cities in Asia, 2009. Available online: http://re.indiaenvironmentportal.org.in/files/mega_cities_report.pdf (accessed on 26 July 2016).

2. Stern, N. The Economics of Climate Change: The Stern Review; Cambridge University Press: Cambridge, UK, 2006; pp. 134-156.

3. Jiang, J.J.; Ye, B.; Ma, X.M. The construction of Shenzhen's carbon emission trading scheme. Energy Policy 2014, 75, 17-21. [CrossRef]

4. Cyranoski, D. What China's latest five-year plan means for science. Nature 2016, 531, 424-425. [CrossRef] [PubMed]

5. Galeotti, M.; Lanza, A.; Pauli, F. Reassessing the environmental Kuznets curve for $\mathrm{CO}_{2}$ emission: A robustness exercise. Ecol. Econ. 2006, 57, 152-163. [CrossRef]

6. He, J.; Richard, P. Environmental Kuznets curve for $\mathrm{CO}_{2}$ in Canada. Ecol. Econ. 2009, 11, 1-11. [CrossRef]

7. Inmaculada, M.Z.; Aurelia, B.M. Pooled mean group estimation for an environmental Kuznets curve for $\mathrm{CO}_{2}$. Econ. Lett. 2004, 82, 121-126. 
8. Lebel, L.; Garden, P.; Banaticla, M.R.N. Integrating carbon management into the development strategies of urbanizing regions in Asia. J. Ind. Ecol. 2007, 11, 61-81. [CrossRef]

9. International Energy Agency (IEA). Energy and Poverty. In World Energy Outlook 2002; International Energy Agency: Paris, France, 2012.

10. Strachan, N.; Pye, S.; Kannan, R. The iterative contribution and relevance of modeling to UK. Energy Policy 2009, 37, 850-860. [CrossRef]

11. McEvoy, D.; Gibbs, D.C.; Longhurst, J.W.S. Urban sustainability: Problems facing the local approach to carbon-reduction strategies. Environ. Plan. C 1998, 16, 423-432. [CrossRef]

12. Streck, C. New partnerships in global environmental policy: The clean development mechanism. J. Environ. Dev. 2004, 13, 295-322. [CrossRef]

13. Steven, S.; Sijm, J. Carbon trading in the policy mix. Oxf. Rev. Econ. Policy 2003, 19, 420-437.

14. Dhakal, S.; Betsill, M.M. Challenges of Urban and Regional Carbon Management and the Scientific Response. Local Environ. 2007, 12, 549-555. [CrossRef]

15. Baranzini, A.; Goldemberg, J.; Speck, S. A future for carbon taxes. Ecol. Econ. 2000, 32, 395-412. [CrossRef]

16. While, A.; Jonas, A.E.G.; Gibbs, D. From sustainable development to carbon control: Eco-state restructuring and the politics of urban and regional development. Trans. Inst. Br. Geogr. 2009, 35, 76-93. [CrossRef]

17. Garg, A.; Bhattachary, S.; Shukla, P.R. Regional and sectorial assessment of greenhouse gas emissions in India. Atmos. Environ. 2001, 35, 2679-2695. [CrossRef]

18. Bristowa, A.L.; Tight, M.; Pridmore, A. Developing pathways to low carbon land-based passenger transport in Great Britain by 2050. Energy Policy 2008, 36, 3427-3435. [CrossRef]

19. Diakoulaki, D.; Mandaraka, M. Decomposition analysis for assessing the progress in decoupling industrial growth from $\mathrm{CO}_{2}$ emissions in the EU manufacturing sector. Energy Econ. 2007, 29, 636-664. [CrossRef]

20. Dimoudi, A.; Tompa, C. Energy and environmental indicators related to construction of office buildings. Resour. Conserv. Recycl. 2008, 53, 86-95. [CrossRef]

21. Yang, C.; McCollum, D.; McCarthy, R. Meeting an $80 \%$ reduction in greenhouse gas emissions from transportation by 2050: A case study in California. Transp. Res. D Transp. Environ. 2009, 14, 147-156. [CrossRef]

22. Yamaguchi, Y.; Shimoda, Y.; Mizuno, M. Proposal of a modeling approach considering urban form for evaluation of city level energy management. Energy Build. 2007, 39, 580-592. [CrossRef]

23. Wu, X.C.; Priyadarsini, R.; Eang, L.S. Benchmarking energy use and greenhouse gas emissions in Singapore's hotel industry. Energy Policy 2010, 38, 4520-4527.

24. Ang, B.W. The LMDI approach to decomposition analysis: A practical guide. Energy Policy 2005, 33, 867-871. [CrossRef]

25. Greening, L.A.; Ting, M.; Krackler, T.J. Effects of changes in residential end-uses and behavior on aggregate carbon intensity: Comparison of 10 OECD countries for the period 1970 through 1993. Energy Econ. 2001, 23, 153-178. [CrossRef]

26. Greening, L.A. Effects of human behavior on aggregate carbon intensity of personal transportation: Comparison of 10 OECD countries for the period 1970-1993. Energy Econ. 2004, 26, 1-30. [CrossRef]

27. Greening, L.A.; Ting, M.; Davis, W.B. Decomposition of aggregate carbon intensity for freight: Trends from 10 OECD countries for the period 1971-1993. Energy Econ. 1999, 21, 331-361. [CrossRef]

28. Geels, F.W. From sectoral systems of innovation to socio-technical systems: Insights about dynamics and change from sociology and institutional theory. Res. Policy 2004, 33, 897-920. [CrossRef]

29. Houlihan, B. Housing Policy and Central/Local Government Relations; Gower Publishing Co.: Avebury, UK, 1988.

30. Rowat, D.C. International Handbook on Local Government Reorganization: Contemporary Developments; Aldwych Press: London, UK, 1980; pp. 594-603.

31. Hempel, L.C. Environmental Governance: The Global Challenge; Island Press: Washington, DC, USA, 1996.

32. Low, N.; Gleeson, B. Justice, Society and Nature: An Exploration of Political Ecology; Routledge: London, UK, 1998.

33. Downie, D.L.; Chasek, P.; Brown, J.W. Global Environmental Politics: Dilemmas in World Politics, 6th ed.; Westview Press: Boulder, CO, USA, 2014.

34. Young, O.R.; Demko, G.J.; Ramakrishna, K. Global Environmental Change and International Governance; University Press of New England: Dartmouth, NH, USA, 1996.

35. Short, J.R. Urban Theory: A Critical Assessment; Palgrave Macmillan: Basingstoke, UK, 2006. 
36. Brenner, N. New State Spaces: Urban Governance and the Rescaling of Statehood; Oxford University Press: Oxford, UK, 2004.

37. Alber, G.; Kern, K. Governing climate change in cities: Modes of urban climate governance in multi-level systems. In Proceedings of the OECD Conference Competitive Cities and Climate Change, Milan, Italy, 9-10 October 2008.

38. Betsill, M.; Bulkeley, H. Transnational networks and global environmental governance: The cities for climate protection program. Int. Stud. Q. 2004, 48, 471-493. [CrossRef]

39. Hooghe, L.; Marks, G. Multi-Level Governance and European Integration; Rowman \& Littlefield Publishers: Lanham, MD, USA, 2001.

40. Francesch-Huidobro, M. Climate change and energy policies in Shanghai: A multilevel governance perspective. Appl. Energy 2016, 164, 45-56. [CrossRef]

41. Feng, J. The beginning and end of the twelfth five-year energy-saving emission reduction decision. South. Weekend 2011, 4, 68-69. (In Chinese)

42. National Bureau of Statistics of China (NBSC). Shenzhen Statistical Yearbook 2015; China Statistics Press: Shenzhen, China, 2015. (In Chinese).

43. Liu, S.G. Shenzhen carbon emissions present situation and countermeasure research. Chin. Acad. Sci. Work. 2012, 11, 26-27. (In Chinese)

44. Medium to Long Term Planning of Shenzhen Low-Carbon Development. Available online: http://govinfo.nlc. gov.cn/gdsszfz/xxgk/szsfzhggwyh/201310/t20131018_4071973.shtml?classid=416 (accessed on 14 July 2016).

45. Wang, M. Use the Natural Gas to “Retake” Shenzhen's Blue Sky. Shenzhen Special Zone Newspaper, 28 June 2013. (In Chinese).

46. Zhu, Y.Q. Development of Renewable Energy in Shenzhen. Shenzhen Sci. Technol. 2006, 7, 54-57. (In Chinese)

47. Zhu, R.W.; Lao, C.Q. Present Situation and Countermeasure of Shenzhen New Energy Automobile Industry Development. Pract. Theory SEZS 2015, 2, 54-61. (In Chinese)

48. De Jong, M.; Wang, D.; Yu, C. Exploring the Relevance of the Eco-City Concept in China: The Case of Shenzhen Sino-Dutch Low Carbon City. J. Urban Technol. 2013, 20, 95-113. [CrossRef]

49. Schreurs, M.A. Multi-level governance and global climate change in East Asia. Asian Econ. Policy Rev. 2010, 5, 88-105. [CrossRef]

(C) 2016 by the authors; licensee MDPI, Basel, Switzerland. This article is an open access article distributed under the terms and conditions of the Creative Commons Attribution (CC-BY) license (http://creativecommons.org/licenses/by/4.0/). 